\title{
Ordering Policies of a Deteriorating Item in an EOQ Model under Upstream Partial Order-Quantity-Dependent Trade Credit and Downstream Full Trade Credit
}

\author{
Zohreh Molamohamadi (iD) and Abolfazl Mirzazadeh \\ Department of Industrial Engineering, Kharazmi University, Tehran, Iran \\ Correspondence should be addressed to Zohreh Molamohamadi; zmmohamadi@gmail.com
}

Received 20 November 2020; Revised 22 March 2021; Accepted 26 March 2021; Published 13 April 2021

Academic Editor: Ioannis Konstantaras

Copyright (C) 2021 Zohreh Molamohamadi and Abolfazl Mirzazadeh. This is an open access article distributed under the Creative Commons Attribution License, which permits unrestricted use, distribution, and reproduction in any medium, provided the original work is properly cited.

\begin{abstract}
In the classical inventory systems, the retailer had to settle the accounts of the purchased items at the time they were received. But in practice, the supplier applies some strategic tools, such as trade credit contract, to enhance his sales channel and offers delay period to his customers to settle the account. Any member of the supply chain may offer full or partial trade credit contract to his downstream level. Full trade credit is the case that the latter is allowed to defer the whole payment to the end of the credit period. In partial trade credit, however, the downstream supply chain member must pay for a proportion of the purchased goods at first and can delay paying for the rest until the end of the credit period. This paper considers a two-level trade credit, where the supplier offers order-quantity-dependent partial trade credit to a retailer, who suggests full trade credit to his customers. An economic order quantity (EOQ) inventory model of a deteriorating item is formulated here, and the Branch and Reduce Optimization Navigator is applied to find the optimal replenishment policy. The sensitivity of the variables on different parameters has been analyzed by applying some numerical examples. The data reveal that increasing the credit periods of the retailer and the customers can decrease and increase the retailer's total cost, respectively.
\end{abstract}

\section{Introduction}

External financing means, such as loans, are reliable sources for companies to fund their operations. However, due to various reasons, including lack of information and debtor's high capital cost, getting external financial sources might be expensive and difficult for the retailers. Since suppliers and retailers (buyers) are operating in the same industry, the former would have better estimation of the demand and as they tend to sell their goods to retailers, they have motivation for lending to them. Therefore, the quite easy access to supplier financing would motivate the buyers to have contract with the suppliers who offer trade credit. Trade credit refers to the case that the supplier allows the buyer to defer payment of the received items.

In the traditional EOQ model, the retailer paid to the supplier for the purchased goods at the time of delivery. In practice, however, the supplier usually offers the retailer to pay with delay. Four types of delay in payment have been considered in the literature: pay as sold, pay as sold after a predetermined delay period, pay after a predefined period, and pay at the next replenishment time (for further information, refer to $[1,2])$. Trade credit, which usually refers to the third type of delay in payment, is beneficial for both supplier and retailer, as the former can use it as a strategy to expand his market and the retailer can benefit from delay period by accumulating revenue and earning interest to reduce his total cost.

Recently, many researchers have focused on trade credit and they are trying to adjust it to the real situation. Haley and Higgins [3] explored the impact of a two-part trade credit contract on the optimal replenishment policy and payment time. Under two-part trade credit contract, the supplier accepts cash discount for payments within a specific period 
and due in a larger delay period. Goyal [4] formulated the mathematical models of the EOQ inventory system, in which the retailer is allowed to defer payment until a predefined period. These research studies are the infrastructures of most of their succeeding papers in trade credit (refer to [5]).

With the objective of maximizing the annual total profit of the retailer, Jaggi et al. [6] determined the optimal replenishment and trade credit policies in a dynamic decisionmaking problem, under two levels of trade credit and nondecreasing deterioration rate. Shah et al. [7] explored the optimal inventory policy for a retailer under two-level trade credit for a deteriorating product which has fixed lifetime. Chen et al. [8] developed an EOQ inventory model in which the partial/full trade credit contract depends on the ordered quantity. Pourmohammad Zia and Taleizadeh [9] established an EOQ inventory model with shortage under order-sizedependent advance and credit payments to optimize the ordering policy. Under order-quantity-dependent trade credit, Yueli et al. [10] assumed the newsvendor model with stochastic demand and shortage and concluded that higher delay periods would increase the profit. When a three-echelon supply chain is assumed, Yang et al. [11] obtained the maximum joint profit of a two-level trade credit for a single product with defective production and repair rate. In order to obtain the optimal fuzzy total cost, Shabani et al. [12] established a two-warehouse mathematical inventory model under trade credit contract. The results revealed that increasing the delay period would result in decreasing the system's total cost. In an EOQ framework with price-sensitive demand and ameliorating items, Mahata and De [13] explored the optimal replenishment policy under two-level trade credit policy. The results reveal that the retailer should propose lower delay period to the customers to increase his profit.

Under trade credit contract and inflation [14], developed a manufacturer-retailer inventory model for deteriorating items with time-dependent demand. The conducted sensitivity analysis showed that when the retailer's delay periods increase, the total cost of the supply chain and the retailer's cost decrease. Aljazzar et al. [15] explored the mathematical inventory model of a three-echelon supply chain under two levels of trade credit and price discounts and concluded that having trade credit and price discounts at the same time increases the supply chain profit more than using each of these mechanisms at a time.

Under full upstream and partial downstream trade credit [16], developed the retailer's ordering strategy model, in which a deteriorating product has a fixed lifetime. Mahata and Chandra Mahata[17] investigated the optimal replenishment and trade credit policies of a retailer who sells deteriorating product with inventory and delay period-dependent demand and offers trade credit to the customer to foster the market competition. They analyzed the sensitivity of the variables on the parameters and provided some useful managerial insights. Zhang and Yuan [18] developed an EOQ inventory model to obtain a retailer's optimal replenishment policies for a single item under upstream order-quantity-dependent trade credit and downstream full trade credit. They supposed that the retailer is offered full trade credit if he orders greater than a specified quantity, and partial trade credit otherwise. Shah and Vaghela [19] formulated an economic production quantity (EPQ) model for a deteriorating item with pricesensitive demand, where the retailer is offered full trade credit and offers partial trade credit to his customers. Under twolevel trade credit policy [20], established a retailer's EOQ inventory model, in which both demand and default risk are sensitive to customer's credit period. Considering a manufacturer and a retailer [21], presented a two-echelon supply chain model for deteriorating items, in which the retailer is offered delay in payment. Mahata et al. [22] assumed deterioration rate and expiration date to develop a three-echelon supply chain, where the supplier and the retailer offer partial delay in payment to their credit-risk customers. Under twolevel trade credit and default risk [23], established an optimal inventory model with credit and time-dependent demand to find the optimal delay period and replenishment time of the retailer and investigated the sensitivity of the variables on the parameters.

Assuming partially backordered shortages [24], established the centralized and decentralized inventory model of a two-echelon supply chain and concluded that the total profit of the supply chain increases in the centralized inventory system. Bhaula et al. [25] considered time-dependent inventory holding cost for noninstantaneous deteriorating items with time and price-dependent demand and applied successive price discounts to utilize the products completely. Assuming nonlinear holding cost and stock-dependent demand [26], developed retailer's EQO inventory model with nonzero ending inventory, in which the retailer is offered trade credit by the supplier. In order to determine the optimal ordering and shortage policies [27], established an EOQ inventory model with shortage for deteriorating products under partial order-dependent delay in payment. Wang et al. [28] proposed a multiitem joint replenishment problem (JRP) under trade credit and grouping constraints to find replenishment policies with the objective of minimizing the overall cost. They provided four intelligent algorithms, including advanced backtracking search optimization algorithm (ABSA), genetic algorithm (GA), differential evolution (DE), and backtracking search optimization algorithm (BSA) to solve their proposed model.

In fuzzy random environments [29], determined the payment and production policies of an imperfect manufacturing system under two-level trade credit with discounted cash flows. They concluded that for higher cash discount rates, the retailer prefers to pay at the end of the delay period to benefit from permissible delay rather than cash discount. Under two-level trade credit [30], established an inventory model for deteriorating items with dynamic demand and default risk to determine the retailer's optimal ordering and inventory policies. Chan and Hsu [31] assumed partial retailer's and full customer's trade credit to find the optimal replenishment time and the no-shortages time to maximize the total profit. Nagpal and Chanda[32] applied partial trade credit strategy in technology market, in which precise demand estimation is critical in decision making.

This research aims to generalize the proposed model of Zhang and Yuan [18] by considering deteriorating items. 
Therefore, it is assumed here that the supplier offers partial trade credit to the retailer for the quantity of orders smaller than a predefined order quantity and allows full trade credit otherwise. It is also supposed that the retailer allows the customers to defer payment until a predefined period. The rest of this paper is organized as follows. The notation and assumptions applied for modeling are addressed in Section 2. In Section 3, the model formulation is discussed. The solution procedure is represented in Section 4, followed by a numerical example and sensitivity analysis in Section 5 . Finally, Section 6 concludes the paper.

\section{Notations and Assumptions}

\subsection{Notations.}

$D$ : the annual demand rate

A: the ordering cost per order

$\mathrm{W}$ : the predefined quantity of orders, at which the full trade credit is allowed

$\mathrm{c}$ : the unit purchasing cost

$\mathrm{p}$ : the unit selling price, $p \geq c$

$h$ : the unit holding cost per year, excluding interest charged

Ie: the interest earned per dollar per year

Ip: the interest charged per dollar in stock per year, Ip $>$ Ie

M: the retailer's credit period offered by the supplier in years

$\mathrm{N}$ : the customer's credit period offered by the retailer in years

$\alpha$ : the percentage of purchased amount which is granted for the trade credit by the supplier, $0 \leq \alpha \leq 1$

$\theta$ : the deteriorating rate, a fraction of the on-hand inventory

T: the retailer's cycle time in years

Tw: the time interval during which $\mathrm{W}$ units are depleted to 0 because of demand and deterioration

T0: the time during which $1-\alpha \mathrm{Q}$ units are depleted

Q: the optimal order quantity of the retailer

TRC: the annual retailer's total relevant cost, which is a function of $\mathrm{T}$

\subsection{Assumptions.}

(1) The demand rate is constant.

(2) The time horizon is infinite.

(3) Deterioration of the product follows an exponential distribution with parameter $\theta$.

(4) Shortages are not permitted.

(5) If the retailer's order quantity is greater than $\mathrm{W}$ (i.e., $T \geq \mathrm{Tw}$ ), then he is allowed full trade credit by the supplier. Therefore, the retailer is allowed to pay the total purchase amount at the end of the delay period. If $Q<W$, then retailer's partial trade credit is granted and he must make a partial immediate payment and pay off the remaining at the end of the delay period M.

(6) The retailer allows his customers to defer payment to the end of delay period, $\mathrm{N}$.

(7) The retailer can accumulate revenue for the items paid by the customers from $\mathrm{N}$ to $\mathrm{M}$. Besides, he would be charged a rate Ip on unpaid balance after $M$ as well as the immediate payments of partial trade credit.

\section{Model Formulation}

The inventory level of the retailer is described based on Figure 1.

The demand and deterioration make the retailer's inventory reduce during 0 and T. So, the retailer's inventory level at any time $t$ in this period is the differential:

$$
\frac{\mathrm{d} I(t)}{\mathrm{d} t}=-D-\theta I(t), \quad 0 \leq t \leq T .
$$

Since $I(T)=0$ is the boundary condition for equation (1), we have the following:

$$
\begin{aligned}
I(t) & =\frac{D}{\theta}\left(e^{\theta(T-t)}-1\right) \quad 0 \leq t \leq T, \\
Q & =I(0)=\frac{D}{\theta}\left(e^{\theta T}-1\right) .
\end{aligned}
$$

Moreover, from equation (3), $T_{W}$ which is the time of depleting $W$ units would be $T_{w}=1 / \theta \ln (W \theta / D+1)$.

For order sizes more than $W$ units, the retailer would be offered full trade credit; otherwise, he must pay $(1-\alpha) c Q$ at the time of purchase and delay paying $\alpha c Q$ until the end of the credit period $(M) . T_{0}$ is defined here as the time during which $(1-\alpha) Q$ units are depleted and can be calculated from equation (3) as $T_{0}=1 / \theta \ln \left(e^{\theta T}-\alpha e^{\theta T}+\alpha\right)$.

Now, the retailer's annual ordering cost, stock holding cost, and deterioration cost are $A / T, h / T \int_{0}^{T} I(t) \mathrm{d} t=$ $h D / T \theta^{2}\left(e^{\theta T}-1-\theta T\right)$, and $c / T\left(D / \theta \quad\left(e^{\theta T}-1\right)-D T\right)$, respectively.

For calculating the total annual cost of the retailer, the interest charged and earned must be calculated as well. For this purpose, the following cases are considered.

Case 1. $T_{W} \leq M-N$.

Subcase 1.1. $T_{W} \leq M-N \leq T$.

Since $T_{W} \leq T$, the retailer is offered the full trade credit. The interest earned and payable is depicted in Figure 2.

As shown in Figure 2, the retailer earns revenue from $N$ to $M$ for being paid by the customers for the items sold during the time $N$ to $\mathrm{M}$. So, the retailer's interest earned is $p I_{e}\left[D(M-N)^{2} / 2 T\right]$. Moreover, his charged interest is $c I_{p}\left[D(T+N-M)^{2} / 2 T\right]$.

Subcase 1.2. $T_{W} \leq T \leq M-N$.

As in the previous subcase, because $T_{W} \leq T$, the retailer receives the full trade credit and as depicted in 


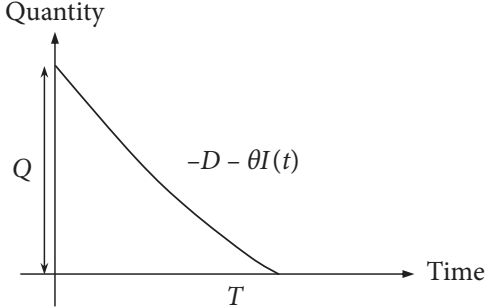

FIGURE 1: Inventory level of the retailer at time $0 \leq t \leq T$.

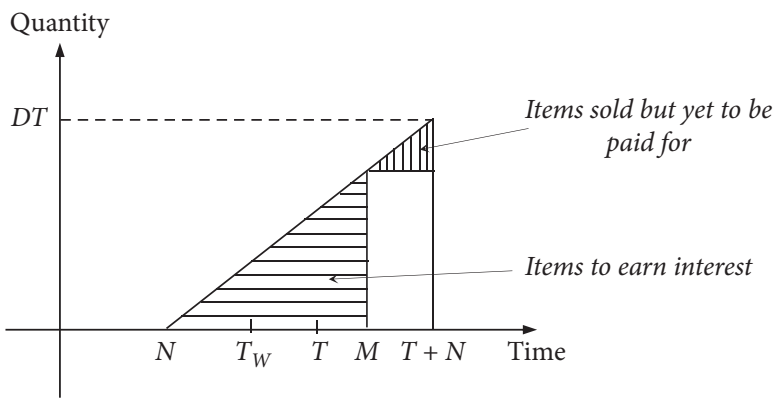

FIgURE 2: The earned and payable interest of the retailer when $T_{W} \leq M-N \leq T$.

Figure 3, the retailer does not bear any payable interest and accumulates $p I_{e} D(M-T / 2-N)$ revenue from $N$ to $M$.

Subcase 1.3. $T<T_{W} \leq M-N$.

Since $T \leq T_{W}$, the retailer must pay for a portion of the purchased goods instantaneously, and the retailer defers payment for the rest. Moreover, $T \leq M-N$ means that $T_{0} \leq T \leq M$. So, according to Figure 4 , the interest earned equals the one in subcase 1.2 and considering equations (2) and (3), the interest charged is

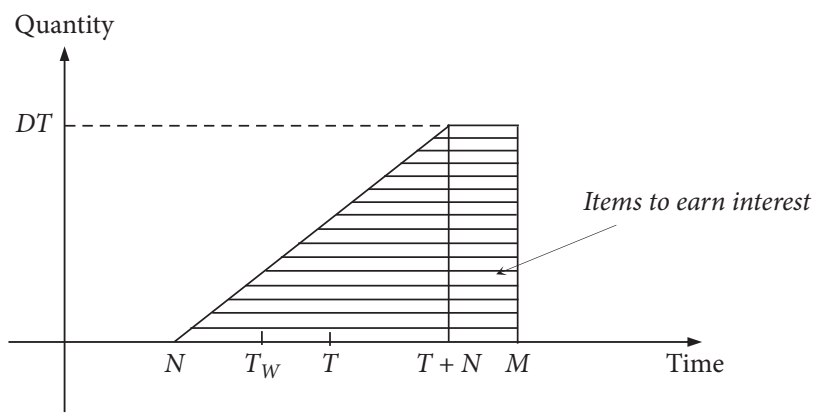

FIgURE 3: The earned and payable interest of the retailer when $T_{W} \leq T \leq M-N$.

$$
\begin{aligned}
& \frac{c I_{p}}{T}\left[\int_{0}^{T_{0}} I(t) d t-\alpha Q T_{0}\right] \\
& =\frac{c I_{p} D}{T}\left[\frac{-\left(e^{\theta\left(T-T_{0}\right)}-e^{\theta T}+\theta T_{0}\right)-\alpha \theta T_{0}\left(e^{\theta T}-1\right)}{\theta^{2}}\right] .
\end{aligned}
$$

Case 2. $M-N \leq T_{W}$.

Subcase 2.1. $M-N \leq T_{W} \leq T$.

The interest earned and the interest charged in this case are exactly as they were calculated in subcase 1.1. Thus, the retailer's earned interest and charged interest are $p I_{e}\left[D(M-N)^{2} / 2 T\right] \quad$ and $c I_{p}\left[D(T+N-M)^{2} / 2 T\right]$, respectively.

Subcase 2.2. $M-N \leq T<T_{W}, T_{0}<T<M$.

Here, as the order quantity is less than $W$ (in other words $\left.\left(T \leq T_{W}\right)\right)$, the retailer receives partial trade credit. Referring to Figure 5, the retailer earns $p I_{e}\left[D(M-N)^{2} / 2 T\right]$ and bears the charged interest of

$$
\begin{aligned}
& \frac{c I_{p}}{T}\left[\left(\int_{0}^{T_{0}} I(t) \mathrm{d} t-\alpha Q T_{0}\right)+\frac{D(T+N-M)^{2}}{2}\right] \\
& \quad=\frac{c I_{p}}{T}\left[\frac{D}{\theta^{2}}\left(e^{\theta\left(T-T_{0}\right)}-e^{\theta T}+\theta T_{0}\right)-\frac{\alpha T_{0} D}{\theta}\left(e^{\theta T}-1\right)+\frac{D(T+N-M)^{2}}{2}\right] .
\end{aligned}
$$

Subcase 2.3. $M-N \leq T<T_{W}, T_{0}<M<T$.

Since $T \leq T_{W}$, the retailer is offered partial trade credit. According to Figure 6, the earned interest is $p I_{e}\left[D(M-N)^{2} / 2 T\right]$ and the charged interest is

$$
\begin{aligned}
& \frac{c I_{p}}{T}\left[\left(\int_{0}^{T_{0}} I(t) \mathrm{d} t-\alpha Q T_{0}+\int_{M}^{T} I(t) \mathrm{d} t\right)+\frac{D(T+N-M)^{2}}{2}\right] \\
& \quad=\frac{c I_{p}}{T}\left[\frac{D}{\theta^{2}}\left(e^{\theta\left(T-T_{0}\right)}-e^{\theta T}+\theta T_{0}\right)-\frac{\alpha T_{0} D}{\theta}\left(e^{\theta T}-1\right)+\frac{D}{\theta^{2}}\left(e^{\theta(T-M)}-1-\theta(T-M)\right)+\frac{D(T+N-M)^{2}}{2}\right] .
\end{aligned}
$$



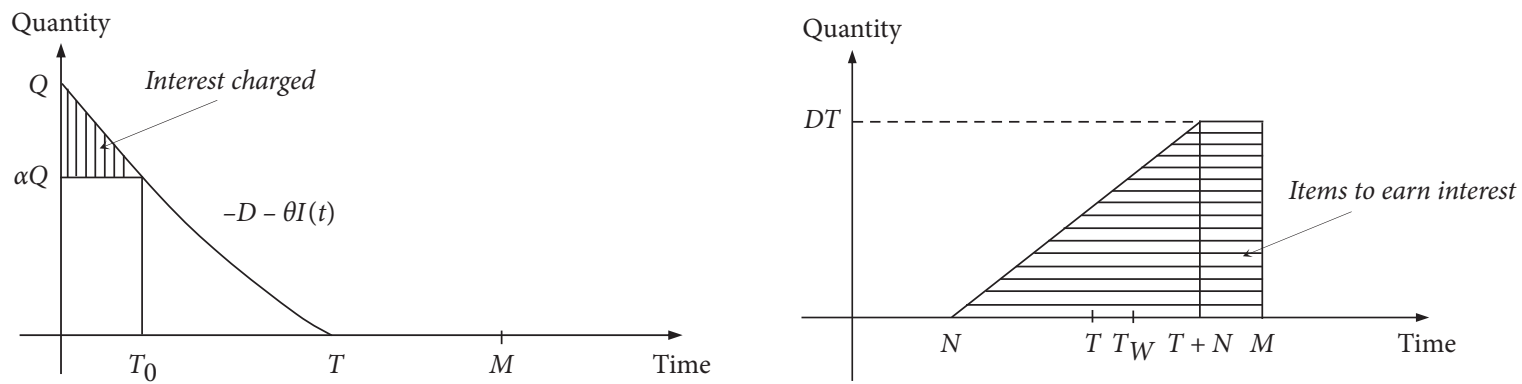

Figure 4: The interest charged (left) and earned (right) of the retailer when $T<T_{W} \leq M-N$.
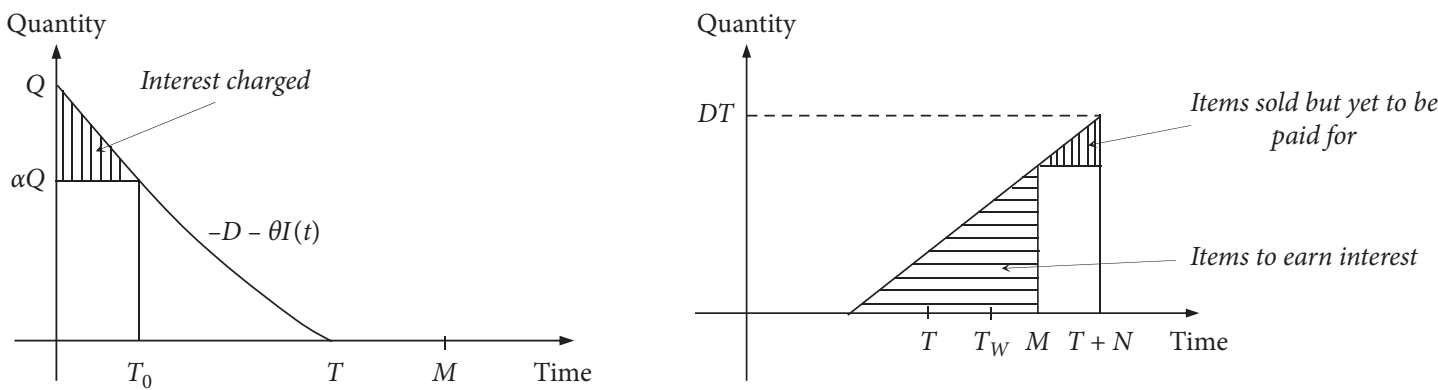

Figure 5: The earned and payable interest of the retailer when $M-N \leq T<T_{W}, T_{0}<T<M$.
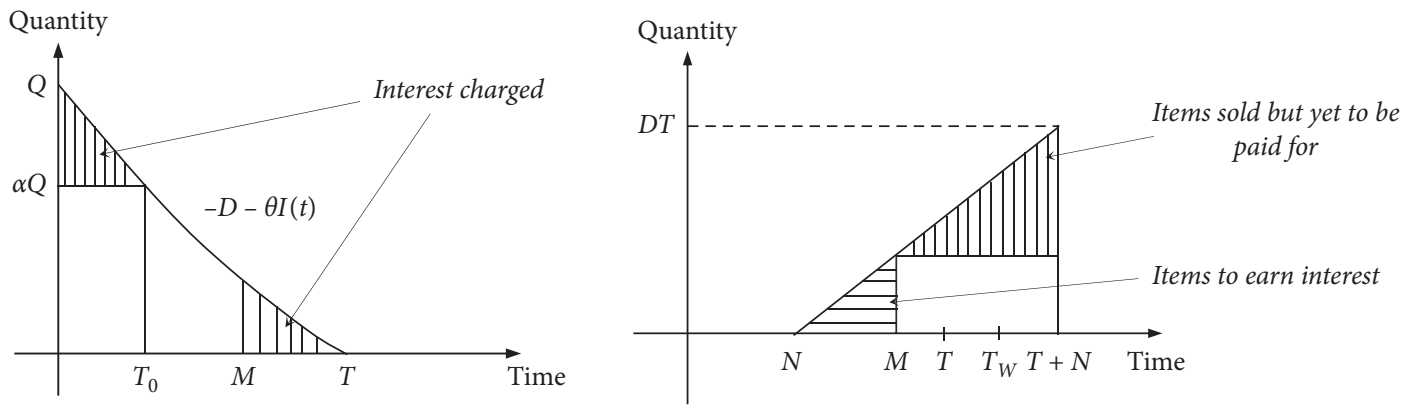

FIgUre 6: The earned and payable interest of the retailer when $M-N \leq T<T_{W}, T_{0}<M<T$.

Subcase 2.4. $M-N \leq T<T_{W}, M<T_{0}<T$.

The retailer earns interest during $N$ to $M$ which equals $p I_{e}\left[D(M-N)^{2} / 2 T\right]$. Moreover, he must pay for $(1-$ $\alpha) Q$ items instantaneously at the purchase time and defer the rest until the end of the delay period. So, the interest charged would be (Figure 7)

$$
\begin{aligned}
& \frac{c I_{p}}{T}\left[\left(\int_{0}^{T} I(t) \mathrm{d} t-\alpha Q M\right)+\frac{D(T+N-M)^{2}}{2}\right] \\
& \quad=\frac{c I_{p}}{T}\left[\frac{D}{\theta^{2}}\left(e^{\theta T}-1-\theta T\right)-\frac{\alpha M D}{\theta}\left(e^{\theta T}-1\right)+\frac{D(T+N-M)^{2}}{2}\right] .
\end{aligned}
$$

Subcase 2.5. $T \leq M-N<T_{W}$.

Similar to subcase 1.3 , the interest charged in this subcase is equal to $c I_{p} D / T\left[\left(e^{\theta\left(T-T_{0}\right)}-e^{\theta T}+\theta T_{0}\right)\right.$ $\left.-\alpha \theta D T_{0}\left(e^{\theta T}-1\right) / \theta^{2}\right]$ and the interest earned is $p I_{e} D(M-T / 2-N)$.
Now, the retailer's inventory model for the aforementioned subcases would be as follows.

Case 1. $T_{W} \leq M-N$.

Subcase 1.1. $T_{W} \leq M-N \leq T$. 

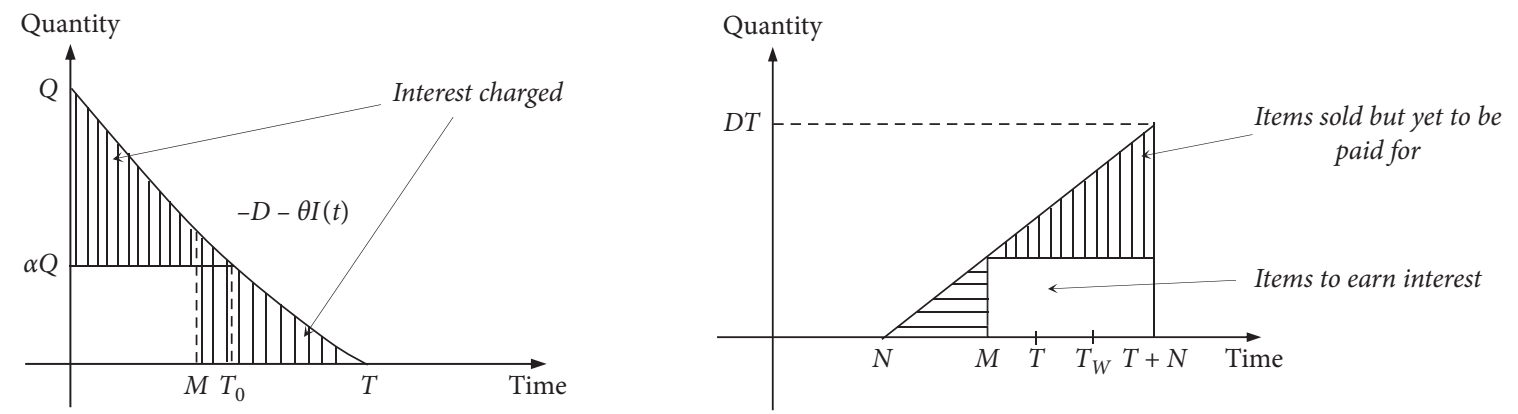

FIgure 7: The earned and payable interest of the retailer when $M-N \leq T<T_{W}, M<T_{0}<T$.

$$
\begin{aligned}
T C_{1-1}= & \frac{A}{T}+\frac{h D}{T \theta^{2}}\left(e^{\theta T}-1-\theta T\right) \\
& +\frac{c}{T}\left(\frac{D}{\theta}\left(e^{\theta T}-1\right)-D T\right) \\
& +c I_{p}\left[\frac{D(T+N-M)^{2}}{2 T}\right] \\
& -p I_{e}\left[\frac{D(M-N)^{2}}{2 T}\right] .
\end{aligned}
$$

$$
\begin{aligned}
T C_{1-3} & =\frac{A}{T}+\frac{h D}{T \theta^{2}}\left(e^{\theta T}-1-\theta T\right) \\
& +\frac{c}{T}\left(\frac{D}{\theta}\left(e^{\theta T}-1\right)-D T\right) \\
& +\frac{c I_{p} D}{T}\left[\frac{-\left(e^{\theta\left(T-T_{0}\right)}-e^{\theta T}+\theta T_{0}\right)-\alpha \theta T_{0}\left(e^{\theta T}-1\right)}{\theta^{2}}\right] \\
& -p I_{e} D\left(M-\frac{T}{2}-N\right) .
\end{aligned}
$$

Case 2. $M-N \leq T_{W}$.

Subcase 1.2. $T_{W} \leq T \leq M-N$.

$$
\begin{aligned}
T C_{1-2}= & \frac{A}{T}+\frac{h D}{T \theta^{2}}\left(e^{\theta T}-1-\theta T\right) \\
& +\frac{c}{T}\left(\frac{D}{\theta}\left(e^{\theta T}-1\right)-D T\right) \\
& -p I_{e} D\left(M-\frac{T}{2}-N\right) .
\end{aligned}
$$

Subcase 2.1. $M-N \leq T_{W} \leq T$.

$$
\begin{aligned}
T C_{2-1}= & \frac{A}{T}+\frac{h D}{T \theta^{2}}\left(e^{\theta T}-1-\theta T\right) \\
& +\frac{c}{T}\left(\frac{D}{\theta}\left(e^{\theta T}-1\right)-D T\right) \\
& +c I_{p}\left[\frac{D(T+N-M)^{2}}{2 T}\right] \\
& -p I_{e}\left[\frac{D(M-N)^{2}}{2 T}\right] .
\end{aligned}
$$

Subcase 1.3. $T<T_{W} \leq M-N$.

Subcase 2.2. $M-N \leq T<T_{W}, T_{0}<T<M$. 


$$
\begin{aligned}
T C_{2-2}= & \frac{A}{T}+\frac{h D}{T \theta^{2}}\left(e^{\theta T}-1-\theta T\right)+\frac{c}{T}\left(\frac{D}{\theta}\left(e^{\theta T}-1\right)-D T\right) \\
& +\frac{c I_{p}}{T}\left[\frac{D}{\theta^{2}}\left(e^{\theta\left(T-T_{0}\right)}-e^{\theta T}+\theta T_{0}\right)-\frac{\alpha T_{0} D}{\theta}\left(e^{\theta T}-1\right)+\frac{D(T+N-M)^{2}}{2}\right]-p I_{e}\left[\frac{D(M-N)^{2}}{2 T}\right] .
\end{aligned}
$$

Subcase 2.3. $M-N \leq T<T_{W}, T_{0}<M<T$.

$$
\begin{aligned}
T C_{2-3}= & \frac{A}{T}+\frac{h D}{T \theta^{2}}\left(e^{\theta T}-1-\theta T\right)+\frac{c}{T}\left(\frac{D}{\theta}\left(e^{\theta T}-1\right)-D T\right)-p I_{e}\left[\frac{D(M-N)^{2}}{2 T}\right] \\
& +\frac{c I_{p}}{T}\left[\frac{D}{\theta^{2}}\left(e^{\theta\left(T-T_{0}\right)}-e^{\theta T}+\theta T_{0}\right)-\frac{\alpha T_{0} D}{\theta}\left(e^{\theta T}-1\right)+\frac{D}{\theta^{2}}\left(e^{\theta(T-M)}-1-\theta(T-M)\right)+\frac{D(T+N-M)^{2}}{2}\right] .
\end{aligned}
$$

Subcase 2.4. $M-N \leq T<T_{W}, M<T_{0}<T$.

$$
\begin{aligned}
T C_{2-4}= & \frac{A}{T}+\frac{h D}{T \theta^{2}}\left(e^{\theta T}-1-\theta T\right)+\frac{c}{T}\left(\frac{D}{\theta}\left(e^{\theta T}-1\right)-D T\right)-p I_{e}\left[\frac{D(M-N)^{2}}{2 T}\right] \\
& +\frac{c I_{p}}{T}\left[\frac{D}{\theta^{2}}\left(e^{\theta T}-1-\theta T\right)-\frac{\alpha M D}{\theta}\left(e^{\theta T}-1\right)+\frac{D(T+N-M)^{2}}{2}\right]
\end{aligned}
$$

Subcase 2.5. $T \leq M-N<T_{W}$.

$$
\begin{aligned}
T C_{2-4}= & \frac{A}{T}+\frac{h D}{T \theta^{2}}\left(e^{\theta T}-1-\theta T\right)+\frac{c}{T}\left(\frac{D}{\theta}\left(e^{\theta T}-1\right)-D T\right)-p I_{e} D\left(M-\frac{T}{2}-N\right) \\
& +\frac{c I_{p} D}{T}\left[\frac{\left(e^{\theta\left(T-T_{0}\right)}-e^{\theta T}+\theta T_{0}\right)-\alpha \theta D T_{0}\left(e^{\theta T}-1\right)}{\theta^{2}}\right] .
\end{aligned}
$$

\section{Solution Procedure}

The created nonlinear programming (NLP) inventory models in this research are solved by Branch and Reduce Optimization Navigator (BARON) in GAMS software. As a solver, BARON uses the branch-and-bound deterministic global optimization algorithms to acquire the global optimum for various problems such as continuous, integer, nonlinear, and mixed-integer nonlinear problems. Although it had been recognized as a technique for solving the combinatorial optimization problems $[33,34]$, it is now applied to more general multiextremal optimization problems $[35,36]$.

Branch-and-bound solves an assumed problem $\mathrm{P}$, by building and solving its relaxation $R$ over successively refined partitions derived through branching in the problem's feasible space.
Figure 8 demonstrates the critical approach behind this methodology, where minimizing a univariate function with two local minima is considered. For this purpose, a relaxation of the problem $(R)$ is firstly developed. In order to find a lower bound on the optimal objective function value of $\mathrm{P}$, named $L$ in Figure $8(\mathrm{a}), \mathrm{R}$ would be solved. Afterwards, an upper bound for the problem is derived by using local minimization and other upper bounding heuristics, which is shown as $U$ in Figure 8(b). If $\mathrm{U}-\mathrm{L}$ is small enough, then $\mathrm{U}$ would be considered as the optimal solution and the procedure is terminated. Otherwise, the feasible region should be subdivided into partition elements, adjoined to open nodes, which must be searched to locate an optimal solution and verify its globality. Selecting a partition element from the open nodes and constructing a new relaxation by taking advantage of its reduced size is the next step. Domain 


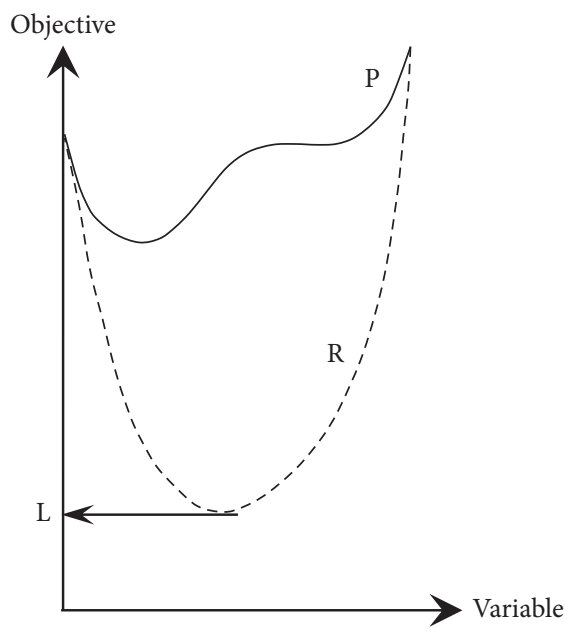

(a)

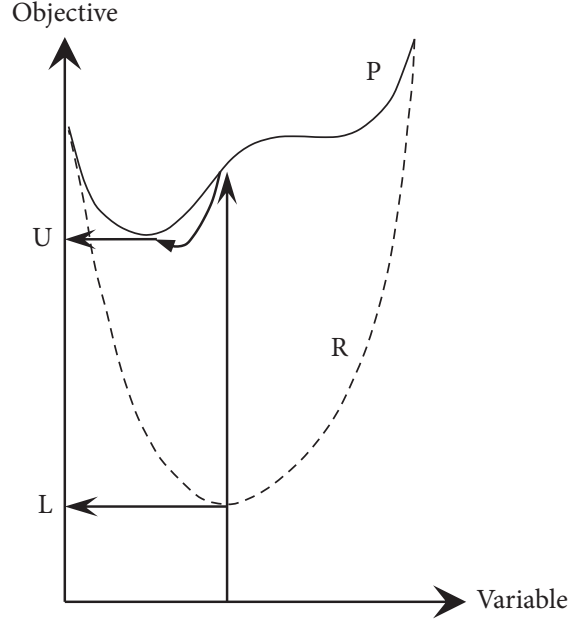

(b)

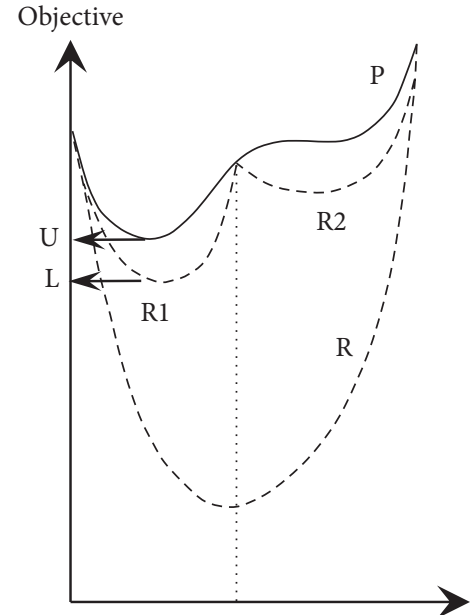

(c)

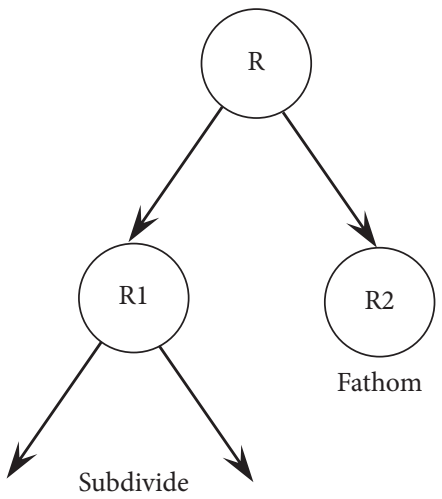

(d)

FIGURE 8: Principles of branch-and-bound [37]. (a) Lower bounding. (b) Upper bounding. (c) Domain subdivision. (d) Search tree.

reduction techniques would be also applied in this process to contract and fathom the search regions, when it is provable that in this way, the algorithm will still terminate with a global optimum (Figure $8(\mathrm{c})$ ). The branch-andbound process is similar to a tree, where the nodes are bounding and the branches demonstrate bounding partitioning (Figure 8(d)) [37]. For more information, refer to $[38]$.

\section{Sensitivity Analysis}

The numerical example applied here to evaluate the effects of parameters on variables is taken from [18]. This example considers an inventory system with the following data: $\mathrm{h}=\$ 10 /$ unit/year, c $=\$ 50 /$ unit, $I_{p}=0.13 /$ year, $I_{e}=0.1 /$ year, $M=0.2$ year, $D=2500, A=\$ 70 /$ order,$W=150$ units, $p=\$ 60 /$ unit, $N=0.13$ year, $\alpha=0.1$, and $\theta=0.05$. The obtained values for $T_{w}, T_{0}, T$, and $T_{C}$ would be $0.0599,0.05392$, 0.5999 , and 1505.836 , respectively.

Moreover, in order to explore the effects of the variables on the parameters, the optimal solution under different values of $A, W, p, N, M$, and $\alpha$ is presented in Tables 1-6.
As it was expected, Table 1 reveals that increasing the cost of order results in greater total cost for the retailer. Moreover, the retailer orders more quantity less frequently to compensate the increased ordering cost. According to Table 2, when the predefined quantity of orders, at which the full trade credit is allowed, becomes greater, the retailer's total cost increases at first and then it decreases and remains constant, while his order quantity increases generally. Here, the cycle time increases gradually first and then remains unchanged. Table 3 shows that a higher value of the selling price reduces the total cost, while the order quantity and the cycle time are constant. The data in Table 4 reveal that when the retailer offers greater credit periods to his customer, his total cost increases, although the order quantity and replenishment cycle remain almost unchanged. Table 5 shows that the greater the credit period offered to the retailer, the more benefit he gains, as his total cost reduces. Table 6 shows that surges in the percentage of granted purchase amount for the trade credit (from 0.1 to 0.7 ) do not have any outstanding effect on the total cost, and the latter increases when the former is changed from 0.7 to 0.9 . The graphical representations of Tables 1-6 are depicted in Figures 9-14. 
TABLE 1: The obtained solutions under different values of $\mathrm{A}$.

\begin{tabular}{lccccc}
\hline A & Tw & T0 & T & Q & TC \\
\hline $\mathbf{7 0}$ & 0.0599 & 0.0539 & 0.0599 & 150.0000 & TC1-2=1505.8361 \\
$\mathbf{8 0}$ & 0.0599 & 0.0539 & 0.0599 & 150.0000 & TC1-2=1672.7527 \\
$\mathbf{9 0}$ & 0.0599 & 0.0563 & 0.0626 & 156.6307 & TC1-2=1836.8919 \\
$\mathbf{1 0 0}$ & 0.0599 & 0.0593 & 0.0658 & 164.8389 & TC1-2=1992.6776 \\
$\mathbf{1 1 0}$ & 0.0599 & 0.0621 & 0.0689 & 172.6584 & TC1-2 $=2141.0768$ \\
$\mathbf{1 2 0}$ & 0.0599 & 0.0647 & 0.0719 & 180.1397 & TC1-1 $=2283.0508$ \\
\hline
\end{tabular}

TABLE 2: The obtained solutions under different values of $\mathrm{W}$.

\begin{tabular}{|c|c|c|c|c|c|}
\hline W & Tw & T0 & $\mathrm{T}$ & Q & TC \\
\hline 150 & 0.0599 & 0.0539 & 0.0599 & 150.0000 & $\mathrm{TC} 1-2=1505.8361$ \\
\hline 165 & 0.0659 & 0.0593 & 0.0659 & 165.0000 & TC1-2 $=1537.3840$ \\
\hline 180 & 0.0719 & 0.0644 & 0.0716 & 179.2979 & TC2-2 $=903.1954$ \\
\hline 200 & 0.0798 & 0.0644 & 0.0716 & 179.2979 & $\mathrm{TC} 2-2=903.1954$ \\
\hline 220 & 0.0878 & 0.0644 & 0.0716 & 179.2974 & TC2-2 = 903.1954 \\
\hline
\end{tabular}

TABLE 3: The obtained solutions under different values of $p$.

\begin{tabular}{lccccc}
\hline$p$ & Tw & T0 & T & Q & TC \\
\hline $\mathbf{6 0}$ & 0.0599 & 0.0539 & 0.0599 & 150.0000 & TC1-2=1505.8361 \\
$\mathbf{7 0}$ & 0.0599 & 0.0539 & 0.0599 & 150.0000 & TC1-2=1403.5997 \\
$\mathbf{8 0}$ & 0.0599 & 0.053 & 0.0599 & 150.0000 & TC1-2=1301.3633 \\
$\mathbf{9 0}$ & 0.0599 & 0.0539 & 0.0599 & 150.0000 & TC1-2=1199.1270 \\
$\mathbf{1 0 0}$ & 0.0599 & 0.0539 & 0.0599 & 150.0000 & TC1-2=1096.8906 \\
\hline
\end{tabular}

TABLe 4: The obtained solutions under different values of $\mathrm{N}$.

\begin{tabular}{lccccc}
\hline $\mathrm{N}$ & $\mathrm{Tw}$ & $\mathrm{T} 0$ & $\mathrm{~T}$ & $\mathrm{Q}$ & $\mathrm{TC}$ \\
\hline $\mathbf{0 . 1 3}$ & 0.0599 & 0.0539 & 0.0599 & 150.0000 & TC1-2 $=1505.8361$ \\
$\mathbf{0 . 1 4}$ & 0.0599 & 0.0548 & 0.0609 & 152.5076 & TC2-2=1079.0639 \\
$\mathbf{0 . 1 5}$ & 0.0599 & 0.0548 & 0.0609 & 152.5076 & TC2-2=1230.2768 \\
$\mathbf{0 . 1 6}$ & 0.0599 & 0.0548 & 0.0609 & 152.5076 & TC2-2 $=1383.5419$ \\
$\mathbf{0 . 1 7}$ & 0.0599 & 0.0548 & 0.0609 & 152.5076 & TC2-2 $=1538.8592$ \\
\hline
\end{tabular}

TABLE 5: The obtained solutions under different values of $M$.

\begin{tabular}{lccccc}
\hline $\mathrm{M}$ & Tw & T0 & T & Q & TC \\
\hline $\mathbf{0 . 2 0}$ & 0.0599 & 0.0539 & 0.0599 & 150.0000 & TC1-2=1505.8361 \\
$\mathbf{0 . 2 1}$ & 0.0599 & 0.0539 & 0.0599 & 150.0000 & TC1-2=1358.9846 \\
$\mathbf{0 . 2 2}$ & 0.0599 & 0.0539 & 0.0599 & 150.0000 & TC1-2=1214.2195 \\
$\mathbf{0 . 2 3}$ & 0.0599 & 0.0539 & 0.0599 & 150.0000 & TC1-2=1071.5408 \\
$\mathbf{0 . 2 4}$ & 0.0599 & 0.0539 & 0.0599 & 150.0000 & TC1-2 $=930.9486$ \\
\hline
\end{tabular}

TABLE 6: The obtained solutions under different values of $\alpha$

\begin{tabular}{lccccc}
\hline$\alpha$ & Tw & T0 & T & Q & TC \\
\hline $\mathbf{0 . 1}$ & 0.0599 & 0.0539 & 0.0599 & 150.0000 & TC1-2=1505.8361 \\
$\mathbf{0 . 3}$ & 0.0599 & 0.0420 & 0.0599 & 150.0000 & TC1-2=1505.8361 \\
$\mathbf{0 . 5}$ & 0.0599 & 0.0300 & 0.0599 & 150.0000 & $T C_{1-2}=1505.8361$ \\
$\mathbf{0 . 7}$ & 0.0599 & 0.0180 & 0.0599 & 150.0000 & $T_{1-2}=1505.8361$ \\
$\mathbf{0 . 9}$ & 0.0599 & 0.0055 & 0.0549 & 137.4089 & $T_{1-3}=1499.8544$ \\
\hline
\end{tabular}



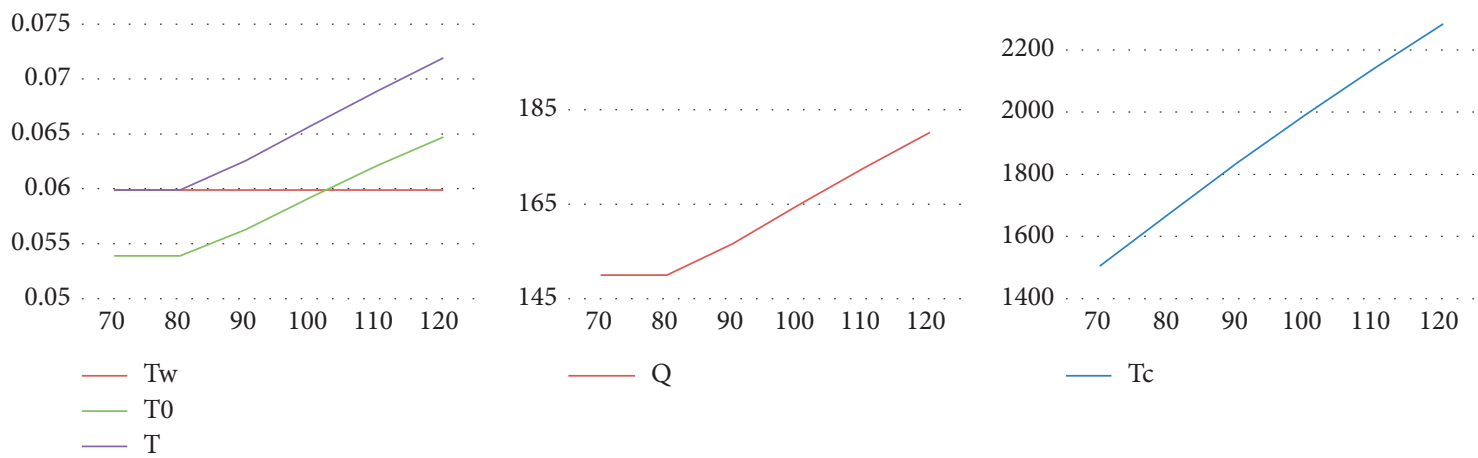

Figure 9: The effect of parameter $A$ on decision variables.
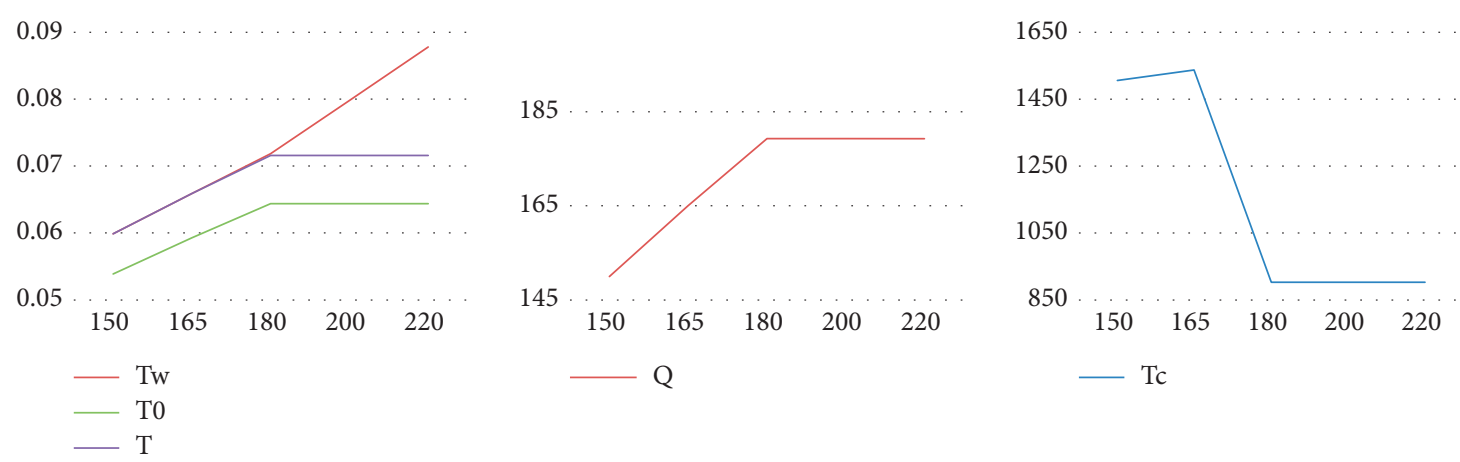

FIgURE 10: The effect of parameter $W$ on decision variables.
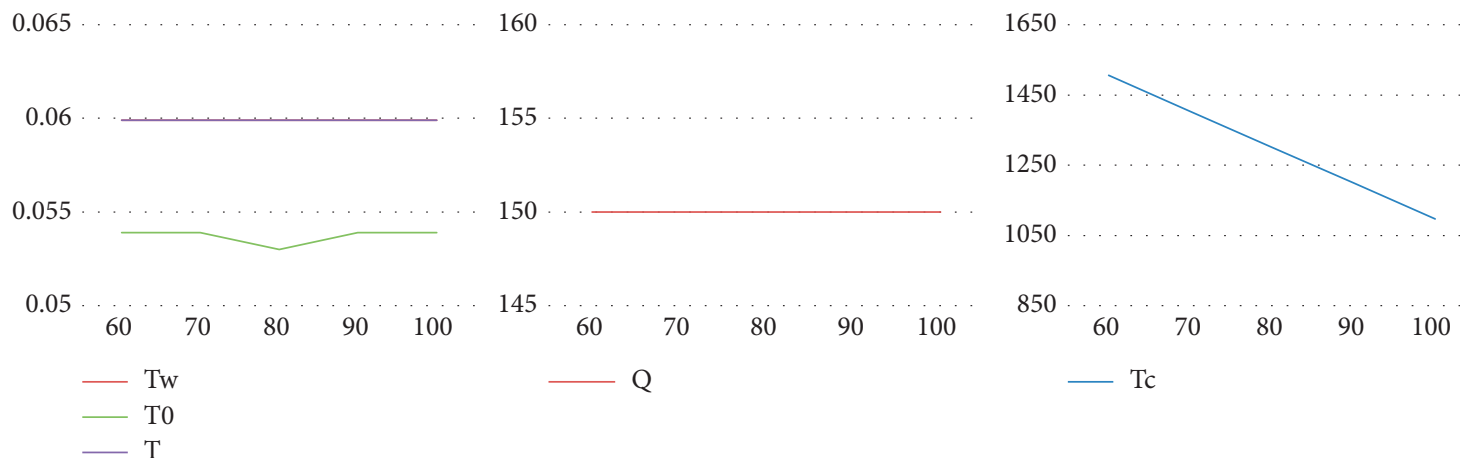

Figure 11: The effect of parameter $p$ on decision variables.
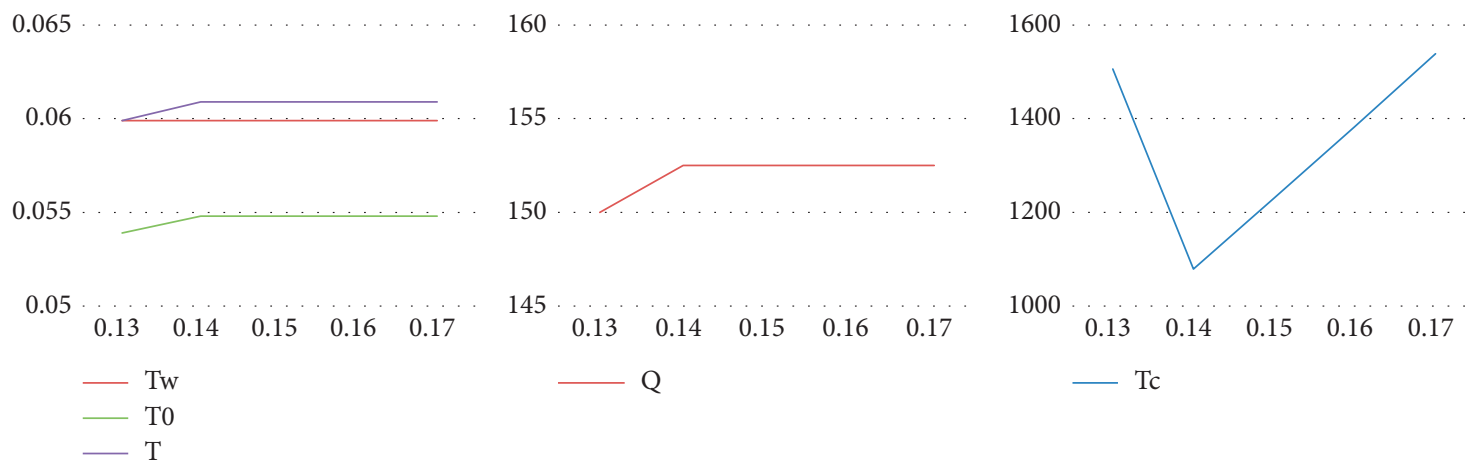

Figure 12: The effect of parameter $N$ on decision variables. 


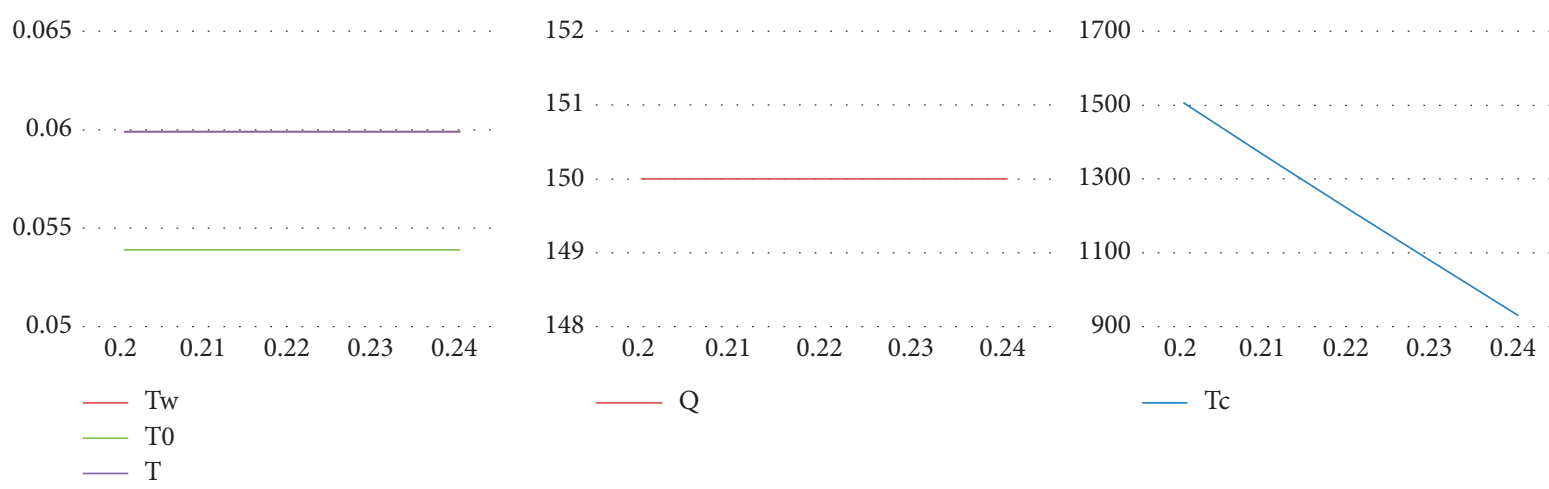

FIgURE 13: The effect of parameter $M$ on decision variables.
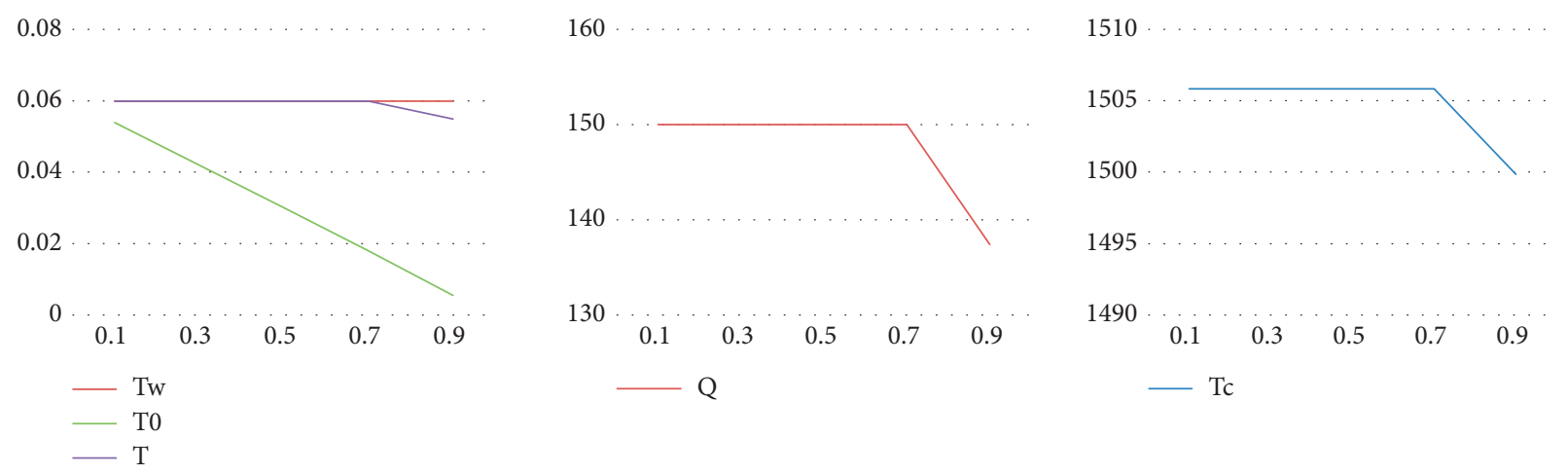

Figure 14: The effect of parameter $\alpha$ on decision variables.

\section{Conclusion}

This paper determines the proper ordering policy of a retailer in an EOQ inventory system. It is considered that if the retailer orders less than a predefined quantity, he must pay for a portion of the purchased goods when he orders and can postpone paying for the rest of the items to the end of the credit period. In the case he orders more than the predetermined quantity, he is offered full trade credit by the supplier. Moreover, two-level trade credit is assumed here, in which the retailer would offer trade credit contract to his customer. The objective of this research is to obtain the retailer's replenishment policy for a deteriorating item in an economic order quantity inventory model through minimizing the retailer's total cost. This paper can be considered the generalized model of Zhang and Yuan [18] in which deterioration rate is considered. The results of the sensitivity analysis can help the managers in inventory policy decision making. It is demonstrated that the higher replenishment cost imposes larger total cost to the retailer. In such a case, the retailer prefers to order more quantity to increase the cycle time and reduce the pressure of the increased ordering cost. Moreover, as it could be predicted, increasing the retailer's credit period benefits him, while the larger values for the customer's delay period generally increase the retailer's cost. Hence, managers must choose the most suitable trade credit value for preventing their system from great losses. As another result, increasing the predefined order quantity of trade credit, from 150 to 180 , would increase the order quantity and decrease the total cost. However, increasing this value from 180 to 200 does not make any considerable change to the results. Besides, the higher the selling price is, the less the total cost would be.

There are several options for future research; shortages, backorder, or lost sale can be considered to generalize the model proposed in this paper. Moreover, for making the research more practical, the model can be considered under parameters' uncertainties. Considering two-echelon supply chain is another potential extension of this research paper.

\section{Data Availability}

The data used to support the findings of this study are given in Section 5, which are taken from Zhang and Yuan [18].

\section{Conflicts of Interest}

The authors declare that they have no conflicts of interest.

\section{Acknowledgments}

This research was supported by Iran's National Elites Foundation.

\section{References}

[1] D. Piasecki, Consignment inventory: what is it and when does it make sense to use it Inventory Operations Consulting LLC, 2004. 
[2] Z. Molamohamadi, M. Rezaeiahari, and N. Ismail, "Consignment inventory: review and critique of literature," Journal of Basic and Applied Scientific Research, vol. 3, no. 6, pp. 707-714, 2013.

[3] C. W. Haley and R. C. Higgins, "Inventory policy and trade credit financing," Management Science, vol. 20, no. 4, pp. $464-471,1973$.

[4] S. K. Goyal, "Economic order quantity under conditions of permissible delay in payments," Journal of the Operational Research Society, vol. 36, no. 4, pp. 335-338, 1985.

[5] Z. Molamohamadi, N. Ismail, Z. Leman, and N. Zulkifli, "Reviewing the literature of inventory models under trade credit contact," Discrete Dynamics in Nature and Society, vol. 2014, Article ID 975425, 19 pages, 2014.

[6] C. K. Jaggi, P. K. Kapur, S. K. Goyal, and S. K. Goel, "Optimal replenishment and credit policy in EOQ model under twolevels of trade credit policy when demand is influenced by credit period," International Journal of System Assurance Engineering and Management, vol. 3, no. 4, pp. 352-359, 2012.

[7] N. H. Shah, D. G. Patel, and D. B. Shah, "Optimal policies for deteriorating items with maximum lifetime and two-level trade credits," International Journal of Mathematics and Mathematical Sciences, vol. 2014, Article ID 365929, 5 pages, 2014.

[8] S.-C. Chen, L. E. Cárdenas-Barrón, and J.-T. Teng, "Retailer's economic order quantity when the supplier offers conditionally permissible delay in payments link to order quantity," International Journal of Production Economics, vol. 155, pp. 291-284, 2014.

[9] N. Pourmohammad Zia and A. A. Taleizadeh, "A lot-sizing model with backordering under hybrid linked-to-order multiple advance payments and delayed payment," Transportation Research Part E: Logistics and Transportation Review, vol. 82, pp. 19-37, 2015.

[10] L. Yueli, M. Jiangtao, and H. Zongyi, "An inventory model with stochastic demand under conditionally permissible delay in payments," in Proceedings of the 27th Chinese Control and Decision Conference CCDC), pp. 6326-6329, Qingdao, China, May 2015.

[11] M. Yang, J. Kuo, W. Chen, and Y. Lin, "Integrated supply chain cooperative inventory model with payment period being dependent on purchasing price under defective rate condition," Mathematical Problems in Engineering, vol. 2015, Article ID 513435, 20 pages, 2015.

[12] S. Shabani, A. Mirzazadeh, and E. Sharifi, "A two-warehouse inventory model with fuzzy deterioration rate and fuzzy demand rate under conditionally permissible delay in payment," Journal of Industrial and Production Engineering, vol. 33, no. 2, pp. 134-142, 2016.

[13] G. C. Mahata and S. K. De, "An EOQ inventory system of ameliorating items for price dependent demand rate under retailer partial trade credit policy," Opsearch, vol. 53, no. 4, pp. 889-916, 2016.

[14] M. Mahmoudinezhad, A. Mirzazadeh, and M. Ghoreishi, “An integrated supply chain model for deteriorating items considering delay in payments, imperfect quality and inspection errors under inflationary conditions," in Proceedings of the Institution of Mechanical Engineers, Part B: Journal of Engineering Manufacture, vol. 231, no. 12, pp. 2197-2210, 2017.

[15] S. M. Aljazzar, M. Y. Jaber, and L. Moussawi-Haidar, "Coordination of a three-level supply chain (supplier-manufacturer-retailer) with permissible delay in payments and price discounts," Applied Mathematical Modelling, vol. 40, no. 22, pp. 9594-9614, 2017.
[16] G. C. Mahata and S. K. De, "Supply chain inventory model for deteriorating items with maximum lifetime and partial trade credit to credit-risk customers," International Journal of Management Science and Engineering Management, vol. 12, no. 1, pp. 21-32, 2017.

[17] P. Mahata and G. Chandra Mahata, "Two-echelon trade credit with default risk in an EOQ model for deteriorating items under dynamic demand," Journal of Industrial and Management Optimization, vol. 13, no. 5, pp. 1-26, 2017.

[18] C. Zhang and L.-L. Yuan, "Economic order quantity models with upstream partial trade credit and downstream full trade credit," Journal of Industrial and Production Engineering, vol. 35, no. 1, pp. 32-40, 2018.

[19] N. Shah and C. Vaghela, "An EPQ model for deteriorating items with price dependent demand and two level trade credit financing," Journal of Advanced Research in Applied Mathematics, vol. 39, no. 2, pp. 170-180, 2018.

[20] C. Zhang, L. Fan, Y. Tian, and S. Yang, "Optimal credit period and lot size policies for a retailer at risk of customer default under two-echelon partial trade credit," IEEE Access, vol. 6, pp. 654295-654309, 2018.

[21] S. Saha, T. Chakrabarti, W. Bengal, and W. Bengal, "International journal of supply and operations management," International Journal of Supply and Operations Management, vol. 5, no. 3, pp. 207-217, 2018.

[22] P. Mahata, G. C. Mahata, and S. K. De, "An economic order quantity model under two-level partial trade credit for time varying deteriorating items," International Journal of Systems Science: Operations \& Logistics, vol. 7, no. 1, pp. 1-17, 2018.

[23] A. Mukherjee and G. C. Mahata, "Optimal replenishment and credit policy in an inventory model for deteriorating items under two-levels of trade credit policy when demand depends on both time and credit period involving default risk," RAIRO - Operations Research, vol. 52, no. 5, pp. 1175-1200, 2018.

[24] S. Ebrahimi, S.-M. Hosseini-Motlagh, and M. Nematollahi, "Proposing a delay in payment contract for coordinating a two-echelon periodic review supply chain with stochastic promotional effort dependent demand," International Journal of Machine Learning and Cybernetics, vol. 10, no. 5, pp. 1037-1050, 2019.

[25] B. Bhaula, J. K. Dash, and M. Rajendra Kumar, "An optimal inventory model for perishable items under successive price discounts with permissible delay in payments," Opsearch, vol. 56, no. 1, pp. 261-281, 2019.

[26] L. E. Cárdenas-Barrón, A. A. Shaikh, S. Tiwari, and G. Treviño-Garza, “An EOQ inventory model with nonlinear stock dependent holding cost, nonlinear stock dependent demand and trade credit," Computers \& Industrial Engineering, vol. 139, Article ID 105557, 2020.

[27] S. Tiwari, L. E. Cárdenas-barrón, A. A. Shaikh, and M. Goh, "Retailer' s optimal ordering policy for deteriorating items under order-size dependent trade credit and complete backlogging," Computers \& Industrial Engineering, vol. 139, Article ID 105559, 2020.

[28] L. Wang, L. Peng, S. Wang, and S. Liu, "Advanced backtracking search optimization algorithm for a new joint replenishment problem under trade credit with grouping constraint," Applied Soft Computing, vol. 86, Article ID 105953, 2020.

[29] P. Mahata and G. C. Mahata, "Production and payment policies for an imperfect manufacturing system with discount cash flows analysis in fuzzy random environments," Mathematical and Computer Modelling of Dynamical Systems, vol. 26, no. 4, pp. 374-408, 2020. 
[30] C. Mahato and G. C. Mahata, "Optimal inventory policies for deteriorating items with expiration date and dynamic demand under two-level trade credit," Opsearch, 2021.

[31] L. M. Chan YL. and S. M. Hsu, An inventory model for perishable items under upstream and downstream trade credit, 2021.

[32] G. Nagpal and U. Chanda, "Economic order quantity model for two generation consecutive technology products under permissible delay in payments," International Journal of Procurement Management, vol. 14, no. 1, pp. 93-125, 2021.

[33] R. J. Dakin, "A tree-search algorithm for mixed integer programming problems," The Computer Journal, vol. 8, no. 3, pp. $250-255,1965$.

[34] A. H. Land and A. G. Doig, "An automatic method of solving discrete programming problems," Econometrica, vol. 28, no. 3, pp. 497-520, 1960.

[35] J. E. Falk, R. M. Soland, S. M. Science, T. S. May, and J. E. Falkt, "An algorithm for separable nonconvex programming problems," Management Science, vol. 15, no. 9, pp. $550-569,1969$.

[36] R. Horst and H. Tuy, Global Optimization: Deterministic Approaches, Springer- Verlag Berlin Heidelberg, New York, NY, USA, 1996.

[37] M. Tawarmalani and N. V. Sahinidis, Convexification and Global Optimization in Continuous and Mixed-Integer Nonlinear Programming: Theory, Algorithms, Software, and Applications, Kluwer Academic Publishers, Dordrecht, Netherlands, 2002.

[38] M. Tawarmalan and N. V. Sahinidis, "Exact algorithms for global optimization of mixed-integer nonlinear programs," in Nonconvex Optimization and Its Applications, Handbook of Global Optimization, P. M. Pardalos and H. E. Romeijn, Eds., vol. 62, pp. 65-85, Springer, Boston, MA, USA, 2002. 